\title{
EXTIRPANDO EXCESSOS E PROMULGANDO AUSÊNCIAS: CIRURGIAS ÍNTIMAS, HIERARQUIAS RACIAIS E NORMALIZAÇÃO DO CORPO FEMININO
}

\author{
REMOVING EXCESSES AND PROMULGATING ABSENCES: \\ INTIMATE SURGERIES, RACIAL HIERARCHIES, \\ AND NORMALIZATION OF THE FEMALE BODY
}

Marcelle Schimitt ${ }^{1}$

\begin{abstract}
RESUMO
Proponho uma discussão a respeito das relações entre cirurgias plásticas íntimas, raça e normalização do corpo feminino através de relatos de pacientes, discursos médicos e da imprensa em conjunto com a história de Sarah Baartman e as concepções acerca de sua genitália, os quais nos sugerem entendimentos a respeito de como estes procedimentos materializam raça e gênero nos corpos a eles submetidos. No contexto destes aprimoramentos, o que escapa à simetria, à coloração clara e ao pouco volume materializa o "disforme" e indesejado. Ao extirpar os "excessos" (seja de pele, cor ou sexo), emerge uma genitália hiperfeminina, contida em suas dimensões e formas, pós-humana. Se os "excessos" da genitália feminina são, até hoje, concebidos no terreno do monstruoso e disgênico, a medicina atual, entretanto, teria as tecnologias e a estética para eliminá-los, trazendo ao corpo o "normal" e o "humano" esperados.
\end{abstract}

Palavras-chaves: Cirurgias íntimas; Normalização; Hierarquias raciais; Sarah Baartman.

\begin{abstract}
I propose a discussion about the relationship between intimate plastic surgery, race, and normalization of the female body through patient reports, medical speeches, and the press, together with the story of Sarah Baartman and the conceptions about her genitalia. The analyzed material suggests how these procedures materialize race and gender in the bodies submitted to them. In the context of these improvements, what escapes symmetry, light coloring, and low volume appears the "misshapen" and unwanted. Thus, by extirpating the "excesses" (whether of skin, color or sex), a hyper feminine genitalia emerges, contained in its dimensions and forms, post-human. If the "excesses" of the female genitalia are, until today, conceived in the terrain of the monstrous and dysgenic, current medicine, however, would have the technologies and aesthetics to eliminate them, bringing to the body the "normal" and the "humanly" expected.
\end{abstract}

Keywords: Intimate surgeries; Normalization; Racial hierarchies; Sarah Baartman.

\footnotetext{
${ }^{1}$ Atualmente é Doutoranda em Antropologia Social pela Universidade Federal do Rio Grande do Sul (UFRGS). Mestra em Antropologia Social (UFRGS).e-mail: marcelle.schimitt@gmail.com
} 


\section{INTRODUÇÃO}

Escala dos seres: (...) muito provavelmente existiram raças humanas hoje desaparecidas. Quero crer, contudo, que todas hajam subsistido, da mesma forma como os brancos, negros, cafres, a quem a natureza deu um avental da própria pele, caindo do ventre ao meio das coxas. (VOLTAIRE, 1764)

Sex $=$ genitals $=$ female body $=$ woman, especially woman of color, who stands as the generic category, the vanishing point of convergence for this family of equations. The genitals of the Hottentot Venus were compared to those of the European prostitute, another degenerate female form.(...) All women, as "the sex" in nineteenth century biologizing discourse, partook in the animality envisioned; but black women were ontologically the essence of animality and abnormality. (HARAWAY, 1989)

Como o próprio título deste trabalho anuncia, tratarei sobre cirurgias íntimas, hierarquias raciais, normalização e aprimoramento do corpo feminino. Contudo, não é incorreto também afirmar que as linhas que seguem versarão especialmente sobre ciência, gênero e raça. Reflexões sobre esta tríade têm sido produzidas por autoras e autores das mais variadas áreas (HARAWAY， 1989; GILMAN,1985; FAUSTO-STERLING， 1995; GOULD， 1990; SCHIEBINGER, 1998; WASHINGTON, 2006; RAGO, 2008; FERREIRA e HAMLIN, 2010). A abordagem deste artigo, entretanto, segue aquilo que foi proposto por M'charek $(2010 ; 2014)$. Ou seja, discorrerei sobre como tecnologias específicas - como as cirurgias íntimas que visam à readequação da estética genital - podem guardar em si mesmas conformações de raça e gênero. Na discussão aqui proposta, as semelhanças e diferenças referentes a tais conformações serão tratadas não como entidades que podem ser descortinadas ou que conferem sentidos ao social, mas como fenômenos específicos que são promulgados em momentos de tensão.

Essa breve introdução tem como objetivo situar a leitora ou o leitor acerca do tema e apresentar rapidamente os fios condutores desta discussão. Portanto, vamos a eles: 1) Antes de tudo, apresentarei alguns breves relatos de pacientes, discursos médicos e da mídia que demonstram de maneira bastante evidente a hipótese de que há um padrão de genitália feminina ${ }^{2}$

\footnotetext{
2 Ao longo deste artigo, quando me refiro à "genitália feminina" estou tratando de um conjunto de estruturas próprio de mulheres cisgênero; isto é, clitóris, pequenos e grandes lábios, canal vaginal, uretra etc. E adoto a
} 


\section{westet \\ Dositse}

que é materializado pelas cirurgias íntimas e pelos clareamentos genitais na mesma medida em que é por eles sustentado. Neste contexto, o mínimo de volume e cor parece ser a estética requerida. 2) Em segundo lugar, volto-me para a discussão sobre como o que hoje compreendemos como esteticamente inadequado para a região genital feminina guarda semelhanças com o que, de algum modo, ainda representa a genitália de Sarah $^{3}$ Baartman. Sugiro que por meio desta história que insiste em se fazer presente, as cirurgias íntimas podem ser pensadas a partir de como materializam a raça e o gênero nos corpos a elas submetidos.

Em 1815, no Dictionnaire des sciences médicales, o naturalista francês Julien-Joseph Virey (1775-1846) afirmava que a natureza sexual das mulheres negras poderia ser demonstrada a partir de suas genitálias, que, em comparação às das mulheres europeias brancas, eram consideradas excessivamente grandes. Essa suposta diferença - tratada de forma extremamente hierarquizante - conferiu à estética genital feminina papel crucial na instauração de certos preconceitos raciais que perduram até hoje (GILMAN, 1985). Cuvier ${ }^{4}$ (1769 -1832), também naturalista e zoólogo francês, apresentava um discurso muito próximo ao de seu contemporâneo Virey. Para ele, a fisionomia das mulheres negras, a cor de suas peles e a forma de suas genitálias eram inerentemente diferentes do restante da população, de modo que esses corpos eram compreendidos como detentores não apenas de um apetite sexual primitivo, como também de símbolos externos que atestariam a sua natureza assustadoramente sexual (GILMAN, 1985). Não somente Virey e Cuvier, mas também Galeno, Voltaire e Darwin, entre tantos outros, concebiam que a sexualidade feminina estaria mais próxima ao primitivo. Tal imaginário ocidental tem como metáfora primordial a história de Sarah Baartman (1789 - 1815), também

\footnotetext{
palavra cisgênero para indicar indivíduos cuja identidade de gênero é a mesma que foi atribuída - em função de suas genitálias - ao nascerem.

${ }^{3}$ Também chamada de Saartjie, que, segundo Gould (1990), significa "pequena Sara" em africâner.

${ }^{4}$ Georges Cuvier foi um naturalista, zoólogo, paleontólogo e médico francês nascido em Montbéliard. Cuvier, um dos nomes mais importantes da história do pensamento biológico, é considerado o pai da anatomia comparada. Durante a primeira metade do século XIX, seus trabalhos e ideias foram referência obrigatória em várias áreas da história natural.
} 


\section{nevite

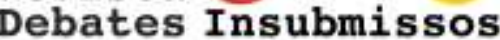

conhecida como Vênus Negra ${ }^{5}$, cujo tamanho dos lábios genitais internos foi associado não apenas a uma hipersexualidade, mas também ao bestial e ao monstruoso.

A aproximação entre o aspecto genital feminino e noções de primitivo, segundo Nurka (2019), pode ser observada também no âmbito das cirurgias íntimas. Conforme a autora, a alteração cirúrgica dos lábios genitais é um fenômeno pós-humano próprio de uma realidade em que nos esforçamos em deixar para trás a "bagunça" do corpo biológico. A estética de uma genitália sem protuberâncias visíveis, também conhecida como "Barbie look", é uma tentativa de alcançar o feminino como uma forma pura (NURKA, 2019, p.14). Nessa visão da evolução tecnológica humana, os lábios genitais tornam-se restos evolutivos funcionalmente inúteis que ninguém deseja. Para Nurka (2019), o trabalho do cirurgião é reduzir os sinais de um pertencimento a espécies biológicas e criar uma genitália feminina pós-humana notavelmente homogênea. Trata-se, sobretudo, de uma tentativa de deixar para trás os vestígios corporais que remetem aos animais.

Proponho aqui que pensemos a genitália pós-humana não somente como algo aprimorado ou pós-orgânico, mas como uma chave de entendimento para a compreensão de certo padrão estético genital a partir da materialização das práticas e discursos acerca do nãohumano ou monstruoso; do humano, ou seja, disciplinado ${ }^{6}$, porém orgânico; e também do póshumano aprimorado. A genitália pós-humana não é menos racializada ${ }^{7}$, demarcada ou situada do que qualquer outra. Ela se constrói a partir do que vem a ser o humano e o não humano. A noção de pós-humano utilizada neste trabalho segue, portanto, o que é proposto por Braidotti (2013): complexo e relacional, afetivo e corporificado, fragmentado e local. Tal perspectiva, é necessário ressaltar, afasta-se de um entendimento binário de distinção entre humano e não humano que foi alicerce do pensamento europeu desde o Iluminismo.

\footnotetext{
${ }^{5}$ Segundo Washington (2006), Sarah Baartman era também conhecida como a Vênus Negra em contraste ao que seria a "verdadeira" Vênus, branca e de beleza considerada inalcançável.

${ }^{6}$ A noção de disciplina utilizada se filia àquela proposta e discutida por Michel Foucault (1999).

${ }^{7}$ Neste artigo não aprofundarei a discussão sobre raça no contexto dos estudos sobre pós-humanismo. Para saber mais sobre este tópico ver Jones e Jones (2017), Rosiek (2018) e Liliwhite (2018).
} 


\section{Debates Insubmissos}

Revista

Ancoro-me na premissa que o "outro" monstruoso é tanto liminal quanto estruturalmente central em nossas percepções de uma subjetividade humana normal (BRAIDOTTI, 1999). A teratologia ${ }^{8}$ evidencia a imbricação das narrativas sobre gênero e raça e o papel delas na construção de discursos científicos sobre o corpo feminino. A conexão é tão extensa que quaisquer análises sobre a experiência corporal das mulheres precisam levar em consideração simultaneamente os efeitos dos discursos e práticas sobre gênero e raça (BRAIDOTTI, 1999). Assim, é também possível dizer que se a história da genitália feminina humana é contada, prioritariamente, através da medicina e da biologia, a história de uma genitália pós-humana não pode ser compreendida somente através destes domínios, porque ela os excede. Isto é, a genitália pós humana é aquela que só pode ser entendida, estudada e discutida a partir de seus "outros": a genitália não-humana, aquela que foi desumanizada, e a genitália humana. É então por meio da história da desumanização de Baartman e de sua genitália que entendo ser possível desenharmos algumas compreensões sobre o que vem a ser uma genitália pós-humana.

A discussão que se segue, contudo, não tem o objetivo de relativizar o sofrimento daquelas mulheres que optam por realizar cirurgias íntimas, mas de indagar algumas das relações possíveis entre os aprimoramentos corporais realizados atualmente, as hierarquias raciais e humanas e as formas como a raça - em seus diversos padrões de ausências e presenças - se materializa nestes contextos.

Antes de voltar-me para a análise e discussão, é necessário anunciar que este artigo é o desdobramento de uma pesquisa que realizei há mais de seis anos, quando desenvolvia meu trabalho de conclusão de curso $^{9}$ na graduação de Ciências Sociais na Universidade Federal do Rio Grande do Sul. Naquele momento, dediquei-me a analisar publicações científicas da área da Cirurgia Plástica e ativismos online acerca das cirurgias íntimas. Também lá, a história de Sarah Baartman estava presente. A discussão teórica e a análise de parte do material empírico contidas neste artigo, entretanto, foram realizadas anos depois, especialmente para serem

\footnotetext{
${ }^{8}$ A teratologia é o estudo das anomalias e malformações do embrião ou feto.

${ }^{9}$ Nota com a referência completa do trabalho. Retirada para preservar o anonimato da autora.
} 
apresentadas no VII Congresso da Associação Portuguesa de Antropologia, que ocorreu em junho de 2019. Ao retornar àquele que foi um dos meus primeiros trabalhos acadêmicos, tinha a intenção de reelaborar e aprofundar certos entendimentos e sanar algumas lacunas que fui descobrindo ou que me foram indicadas ao longo do tempo. A tentativa deu origem ao texto que se sucede.

\title{
2. PEQUENA E BRANCA: A GENITÁLIA FEMININA E SUAS "AUSÊNCIAS"
}

\begin{abstract}
"Não há um padrão estético genital ideal, entretanto, muitas mulheres consideram harmônicos lábios vaginais pequenos e simétricos que não sobressaiam aos grandes lábios, um capuz clitoriano curto, sem dobras adicionais ou tecido excedente, grandes lábios sem excesso de tecido subcutâneo e um monte pubiano com leve convexidade." (BATTISTI et al., 2018)
\end{abstract}

Há algum tempo sabemos dos perigos de tratar as coisas a partir de seus opostos ou complementares, algo que abafa as multiplicidades, as encarcera em pares ingênuos e sufocantes ${ }^{10}$. Mas antônimos também guardam em si uma confusão poderosa a partir da qual se sobressai uma riqueza de modos que não podemos perder de vista. Seguindo ao encontro das confusões, pequena e branca/grande e negra é o par que aqui será pensado - através do que produz - em relação às genitálias femininas e às cirurgias íntimas.

De acordo com a Sociedade Internacional de Cirurgia Plástica (2017; 2018), em 2017 as cirurgias íntimas foram os procedimentos que mais cresceram em quantidade em relação ao ano anterior, representando um aumento de $23 \%$ no mundo todo ${ }^{11}$. No total, foram 206.846 intervenções realizadas em genitálias femininas, 28.365 (mais de 13\% em relação ao total) somente no Brasil, país que mais realizou cirurgias íntimas neste período. De acordo com o DATASUS (2019), Departamento de Informática do Sistema Único de Saúde, em 2018 foram

\footnotetext{
${ }^{10}$ Sobre esta discussão em especial, ver "Dualismos em Duelo", de Anne Fausto Sterling (2002).

${ }^{11}$ Dados referentes ao Internacional Survey on Aesthetic/Cosmetic Procedures Performed in $2017^{19}$. Em dezembro de 2019 foi divulgado o survey realizado em $2018^{20}$, desenvolvido pela mesma instituição, a International Society of Aesthetic Plastic Surgery, que demonstra que naquele ano foram realizadas 18.476 labioplastias, cirurgias de redução dos lábios genitais internos, no Brasil e 132.664 no total de países pesquisados.
} 


\section{westet

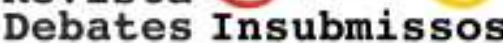

aprovadas 1.507 Autorizações de Internação Hospitalar (AIH) ${ }^{12}$ referentes ao tratamento cirúrgico de hipertrofia dos pequenos lábios. Isto é, nos últimos anos estas intervenções estão sendo realizadas de modo expressivo também por meio do sistema público de saúde, o que nos leva a inferir que, de algum modo, esses procedimentos são classificados como um problema de saúde pública, e não somente como "aprimoramento" ou melhoramento estético corporal.

Hoje, no Brasil, o procedimento mais realizado na área genital feminina é a redução dos pequenos lábios ${ }^{13}$, a labioplastia, que pode ser feita concomitantemente a outras cirurgias, como a de diminuição do capuz do clitóris, que foi o que ocorreu no caso de Renata. A conheci em um grupo da rede social WhatsApp dedicado à discussão sobre cirurgias íntimas femininas e, alguns dias depois, conversamos particularmente sobre a sua experiência. No grupo, as integrantes trocavam experiências, compartilhavam fotos de antes e depois das intervenções e dicas sobre o período de recuperação. Dividiam seus medos e apreensões, bem como as insatisfações com a estética de suas genitálias, principalmente no caso daquelas que ainda não haviam realizado a cirurgia. O grupo foi criado em setembro de 2017, mas comecei a participar somente em março de 2019, quando tive acesso a ele por indicação de uma postagem de discussão sobre cirurgias íntimas na rede social Facebook. Ao me apresentar como pesquisadora às demais integrantes, algumas delas se dispuseram a relatar suas experiências em uma conversa privada via mensagens.

$\mathrm{Na}$ ocasião em que conversamos, Renata contou-me ${ }^{14}$ que havia realizado os dois procedimentos há pouco mais de duas semanas e que - apesar dos 40 anos de idade - pensava

\footnotetext{
${ }^{12}$ A Autorização de Internação Hospitalar (AIH) é o instrumento de registro utilizado por todos os gestores e prestadores de serviços do Sistema Único de Saúde (SUS) e apresenta como característica a proposta de pagamento por valores fixos dos procedimentos médico-hospitalares onde estão inseridos os materiais que devem ser utilizados, os procedimentos que são realizados, os profissionais de saúde envolvidos e estrutura de hotelaria. Fonte:

http://www.consultaesic.cgu.gov.br/busca/dados/Lists/Pedido/Attachments/439293/RESPOSTA_PEDIDO_PRO TOCOLO $\% 20-\% 2025820003924201520 \% 20 \% 20$ DEFINIO $\% 20$ DE $\% 20$ AIHS $\% 20$ E $\% 20$ REGRAMENTO.pdf> último acesso em: 25 de janeiro de 2021

${ }^{13}$ Dado referente ao Internacional Survey on Aesthetic/Cosmetic Procedures Performed in 2017 (2018).

${ }^{14}$ Os depoimentos, coletados entre março e abril de 2019, tiveram permissão para serem publicados desde que, como previamente acordado, suas identidades não fossem reveladas.
} 


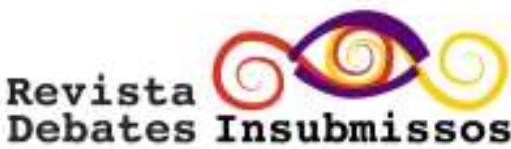

em se submeter a essas cirurgias desde muito jovem, quando notou ser diferente esteticamente da mãe e da irmã. Além dos procedimentos cirúrgicos, relatou estar utilizando hidroquinona ${ }^{15}$ com o objetivo de clarear a área genital externa.

Ao se referir à estética de sua genitália antes da realização dos procedimentos, Renata revelou ter problemas em se relacionar sexualmente em decorrência da aparência ser, em suas palavras, "grotesca, nada feminina". A menção ao formato da genitália enquanto algo "grotesco", muito provavelmente no sentido de algo relacionado ao bizarro, estapafúrdio, primitivo, sugere pensar naquilo que escapa às formas adequadas, no que excede às normas e reside na extravagância. Cabe então como solução possível a diminuição e readequação do formato, seja dos pequenos lábios, seja do clitóris. A aparência "feminina" da genitália almejada por Renata, em comparação ao grotesco, seria o seu contrário. Algo dentro de uma formatação, obedecendo a um tamanho, formato e cor: pequena e branca. Sobre o resultado das cirurgias, Renata disse: “Tá melhor que antes, sem os lábios pra fora, só estou preocupada com a região do clitóris porque acho que não ficará totalmente pra dentro, mas já está ótimo também, porque antes era bem pior".

Assim como Renata, Andreia, que também conheci a partir do grupo de discussões, almejava realizar o procedimento desde a adolescência, quando se informou pela primeira vez sobre as possibilidades de alterar a aparência da genitália externa. Quando conversamos contoume que havia se submetido ao procedimento de redução dos lábios havia um mês, com 41 anos, e relatou se sentir "liberta de algo que não era seu e com isso mais poderosa". A recuperação, contudo, não estava sendo um processo tranquilo. No segundo dia após a cirurgia, Andreia sofreu uma hemorragia e foi para a emergência de um hospital na cidade de São Paulo, onde foi medicada com anticoagulantes. Apesar do acontecido, disse já estar recuperada e vivendo seu cotidiano com normalidade.

\footnotetext{
15 A hidroquinona é um composto que atua nas células produtoras de melanina, os melanócitos, bloqueando a produção e aumentando a degradação dos melanossomos, corpúsculos intra-celulares que armazenam a melanina. É principalmente utilizada para o clareamento da pele.
} 


\section{Debates Insubmissos}

Revista

Rafaela, por sua vez, disse ter decidido realizar a cirurgia - também de redução dos pequenos lábios - para se sentir melhor consigo mesma. Em suas palavras: “o que me incomodava eram os pequenos lábios serem "saltados" para fora. Ficava marcando em biquínis, saindo para fora nas calcinhas, doía para andar de bicicleta (...) agora tenho liberdade de usar a roupa que eu quiser sem me preocupar com o excesso de pele que eu tinha". A descrição de Rafaela, que tinha apenas 17 anos, alinha-se às experiências de Andreia e Renata no sentido em que a preocupação primeira dessas três mulheres repousa sobre o excesso de volume da área genital. Nenhuma delas teve a intenção de realizar um procedimento que conferisse um espessamento da área. Ao contrário, preocuparam-se em extirpar um "excedente" que, nas palavras de Renata era "grotesco e nada feminino". No grupo dedicado a discussão sobre cirurgias íntimas, dentre tantas experiências e dicas compartilhadas, em mais de uma ocasião as participantes sugeriram o site cirurgia.net ${ }^{16}$ para aquelas que pediam por indicações de médicos ou que procuravam por fotografias de antes e depois dos procedimentos. A página composta por fóruns sobre os mais diversos tipos de cirurgias plásticas e experiências pessoais de pacientes que já realizaram os procedimentos - disponibilizava acesso a uma variada gama de depoimentos postados pelas pacientes. Apenas sobre labioplastias haviam mais de 250 experiências compartilhadas, cada uma delas com inúmeros comentários, perguntas e imagens. É também com base nestes depoimentos, acessados por mim durante os meses de maio e abril de 2019, que construo algumas das reflexões aqui presentes.

O sentimento de não se encaixar dentro de uma normalidade esperada afeta estas mulheres de modo intenso. Nos relatos, é possível vislumbrar certa continuidade entre os discursos que atrelam a estética genital a algo disforme e anômalo. O incômodo é tão profundo a ponto de impedi-las de ter relações sexuais, realizar exames ginecológicos e até mesmo consultar com cirurgiãs ou cirurgiões plásticos a fim de solicitar a cirurgia íntima. O relato de

\footnotetext{
${ }^{16}$ Cirurgia.net é um site voltado para o compartilhamento de informações sobre tratamentos estéticos e cirurgias plásticas. Na página constam fotos, vídeos, artigos, recomendações, contatos de profissionais da área e experiências de pacientes que realizaram procedimentos. O Cirurgia.net está presente em 9 países, Espanha, Itália, França, México, Brasil, Argentina, Chile, Colômbia e Alemanha. O site é financiado com contratos anuais de médicas e médicos que aparecem como destaque na página. Tais informações são basicamente as únicas encontradas a respeito do empreendimento online e estão todas disponíveis na aba "Quem somos" do Cirurgia.net.
} 


\title{
Revista \\ Debates Insubmissos
}

Jamile, umas das mulheres que compartilhou sua história no site cirurgia.net, aponta não somente a precocidade com que recorreu ao procedimento como também o intenso sentimento de estranheza com o próprio corpo.

\begin{abstract}
Conversei com minha mãe e pedi a ela que me levasse a um ginecologista já que só tenho 16 anos, no dia minha mãe não pode ir então acabei indo com minha tia, e ela [a médica] me aconselhou dizendo que não ia ficar como eu imagino porque mesmo que ela retire o excesso de pele na parte de cima [no clitóris] que me incomoda bastante ela não pode mexer, ainda sim quero fazer o procedimento, e tenho que voltar lá com minha mãe, isso acaba com minha autoestima e me sinto uma extraterrestre."17
\end{abstract}

Não apenas Jamile, mas uma infinidade de outras mulheres traz em seus depoimentos menções a uma estética que causa desconforto e constrangimento. "É uma coisa muito feia, saía para fora"; "é horrível, tenho nojo demais", "o volume fica enorme em algumas calças"; "queria apenas tirar o excesso"; "não consigo me trocar na frente de amigas". Tal estranhamento materializa-se no "excesso" - de pele, volume ou cor - que se inscreve nestes corpos. Excesso este que não apenas se faz presente por meio de um incômodo ou sentimento de inadequação, mas que também faz emergir uma falta ou ausência esperada, perseguida e corporificada através das cirurgias íntimas.

Nestes breves relatos, o modelo ideal de genitália parece ser aquele que não comporta excessos. Mais belo e feminino será, quanto mais próximo estiver do "mínimo". Além de pequena, a genitália também deve ser a mais alva possível. A insatisfação de algumas mulheres não se limita ao formato, mas abrange também a coloração da genitália que muitas vezes não é, para elas, suficientemente clara. Desde a hidroquinona - utilizada por Renata - até peelings e lasers, há uma gama de tecnologias disponíveis a fim de clarear, especificamente, a área genital. A matéria "Eles preferem as rosas"18 da revista Alfa ${ }^{19}$, voltada ao público masculino, apresentava no início da década passada um discurso bastante explícito que reiterava um modelo de genitália de coloração clara. De acordo com o estudo citado pela matéria, uma vulva rosada é associada, pelos homens pesquisados, à juventude e ao fato de a mulher não estar

\footnotetext{
${ }^{17} \mathrm{O}$ depoimento foi transcrito sem alterações ou correções gramaticais a fim de preservar seu conteúdo e a forma de expressão originalmente utilizada.

${ }^{18}$ Disponível em http://revistaalfa.abril.com.br/sexo/sexo/os-homens-preferem-as-rosas/ Acesso em:25 abr. 2019

${ }^{19}$ A revista Alfa foi publicada e distribuída pela Editora Abril entre setembro de 2010 e agosto de 2013 no Brasil.
} 
grávida ou menstruada, o que sugeriria estar apta para o sexo (leia-se heterossexual e reprodutivo). Este texto, analisado na pesquisa que realizei em 2014, ainda é bastante representativo de como não somente o tamanho, mas também a cor das genitálias suscita discussões.

Relativo ao tamanho, sublinho que há alguns padrões estéticos que enquadram - ou não - a aparência externa da genitália dentro de um espectro de normalidade. Exemplo disso é a categoria "hipertrofia dos pequenos lábios", designação para uma anormalidade da área genital, que, segundo Braun (2000), possui definições diversas, tais como: lábios internos iguais ou maiores a 4 centímetros, normalmente associados a problemas funcionais, ou de 3 a 4 centímetros, considerados como hipertrofia moderada. Para outros, contudo, a hipertrofia consiste em lábios internos iguais ou maiores a 5 centímetros $^{20}$. Não há, então, uma definição precisa. Todavia, existe um critério comumente aceito de que os lábios menores devem estar cobertos e envoltos pelos grandes lábios genitais (BRAUN, 2000).

O tamanho ideal também pode ser pensado em relação ao que se espera do corpo feminino em relação ao masculino, amplamente compreendido como seu oposto. Tal noção fica bastante evidente no excerto de artigo médico que trarei logo abaixo. Antes, contudo, situo rapidamente que a contraposição entre corpos masculinos e femininos tem uma história bastante particular e que já foi amplamente discutida por Laqueur (2001). Segundo o autor, as diferenças entre os sexos, bem como a ideia de dois sexos biológicos, são historicamente situadas. Esse modelo, que data apenas do século XVIII, se diferencia da compreensão, advinda dos gregos, de que haveria apenas um sexo, onde as diferenças entre mulher e homem não seriam de uma natureza biológica, mas se dariam a partir de uma hierarquia de graus de perfeição.

Ao descrever e estabelecer padrões a respeito de genitálias femininas, o artigo científico de Sperli et al. (2011), "Tratamento cirúrgico da hipertrofia clitoriana", apresenta diversas comparações a um modelo de corpo masculino. O corpo feminino é retratado como aquele que comporta órgãos análogos a uma matriz primeira e central: o homem. As particularidades do

\footnotetext{
${ }^{20}$ Mais informações sobre os diferentes tipos de classificação em Malone (2013, p.4).
} 
clitóris e demais estruturas genitais femininas são, dessa maneira, explicadas e compreendidas apenas a partir do seu equivalente e oposto masculino. No trecho abaixo - um compilado de frases retiradas de uma única página da publicação - há cinco menções à semelhança das estruturas genitais femininas cisgênero ao pênis.

(...) o clitóris é homólogo ao pênis, sendo também um órgão erétil, estando encoberto pelos lábios menores da vulva quando flácido [...]. Tem um ligamento semelhante ao pênis [...]. Assim, como o pênis, o clitóris está inserido à sínfise púbica pelo ligamento suspensor [...]. A semelhança do pênis, o clitóris é altamente importante no estímulo sexual feminino [...]. Por mecanismo semelhante ao observado no homem, o clitóris sofre mecanismo de ereção na vigência de estímulo parassimpático. (SPERLI et al, 2011, p. 315)

Sugiro que a presença insistente da genitália masculina para explicar e desenhar os contornos do clitóris e demais partes auxilia na conformação de ausências a partir das quais a genitália feminina passa a ser materializada. Se no século II d.C. Galeno nos apresentou um modelo de compreensão do corpo feminino composto fundamentalmente da retenção interna de estruturas masculinas (LAQUEUR, 2001), hoje algumas noções estéticas parecem não se afastar muito disso. Aqui, assim como lá, o feminino irrompe como o inverso, uma invaginação do masculino. A invaginação nada mais é do que uma dobradura que cria um bolso, e o que teima em desdobrar-se para fora deve ser cirurgicamente eliminado. Dentre tantas possibilidades, materializa-se novamente a "falta".

\section{PRESENÇAS AUSENTES E PERMANÊNCIAS INCÔMODAS}

É possível pensar as cirurgias íntimas a partir de inúmeras relações que estabelecem e por meio das quais também se conformam. Neste momento, escolho tratar - prioritariamente de raça e suas associações. Sugiro que, no contexto da estética genital, não apenas a cor estaria relacionada a raça, mas também o tamanho. Nos últimos seis anos tenho acompanhado essa temática e devo admitir que só agora começo perceber algumas presenças que eram, para mim, até então ausentes. Assim, não vejo outro caminho senão o de tratar o padrão estético "branca e pequena" enquanto um caso muito específico em que a raça pode ser tomada como uma presença ausente, nos termos de M'charek (2014). 


\section{wasto \\ Debates Insubmissos}

Em “Race, time e folded objects”, Amade M'charek (2014) traz a presença ausente como um modo de pensar a raça na história da sequência de DNA humano. Se o objeto trabalhado pela autora em pouco se relaciona com as cirurgias íntimas, a abordagem proposta por ela, por outro lado, fornece aparatos interessantes para um estudo dos fenômenos através de padrões de semelhança e diferença, razão pela qual entendo ser possível aproximar seu estudo da presente pesquisa. $\mathrm{O}$ ponto fulcral de sua proposta, em meu entendimento, reside no fato da autora (2014) importar-se especialmente em como um objeto específico carrega e promulga história, o que pode ser melhor compreendido a partir da imagem do "objeto dobrado", que em vez de deixar a história para trás, decreta de forma ressoante a sua existência. O argumento de M'charek (2014) é o de que conceder história aos objetos - em seu caso particular, o DNA - e atentar para a temporalidade deles é fundamental para a compreensão das políticas que articulam. Assim, para tratar do tempo, é necessário que pensemos a partir de uma noção de tempo topológico. Um tempo que pode ser amassado e dobrado de múltiplas formas, em contraposição a uma temporalidade linear, e que tem como um de seus efeitos a história emergir através dos objetos.

Pensar a raça a partir de uma perspectiva histórica e temporal, como sugerido por M'charek (2014), nos ajuda a entendê-la a partir de suas oscilações. Não mais como um objeto (no singular), mas como um padrão de elementos variados que se deslocam entre presença e ausência. Tendo como ponto de partida um tempo não linear e um entendimento de raça como algo que desliza por diferentes conformações (discursivas, materiais, políticas, históricas, etc.), proponho uma "dobra temporal” que aproxima as práticas de cirurgias íntimas atuais e a história de Sarah Baartman ${ }^{21}$. Creio que ao pensarmos a estética genital "grotesca", aludida por Renata, em conjunto com a conhecida história - forçadamente ausente de uma memória ocidental - de

\footnotetext{
${ }^{21}$ Circunscrito a um âmbito mais local, Rohden ${ }^{27}$ apresenta o caso de Joanna Maria de Jesus, mulher escravizada de 18 anos de idade que, ao que se tem notícia, é o único caso registrado de cliteridectomia no Brasil no final do século XIX. A intervenção foi realizada pelo médico Victor de Amaral e publicada em 1892 no Brasil Médico. Segundo Amaral, Joanna apresentava um tumor localizado na região dos pequenos lábios genitais. Segundo Rohden ${ }^{27}$, o médico descobriu, algum tempo depois, que o que ele achava ser um tumor era, na verdade, o clitóris de Joanna.
} 
Baartman, cuja genitália dissecada encontrava-se até o ano de 1985 no Musèe de L'Homme em Paris, é possível produzir outros entendimentos sobre raça, cirurgias íntimas e medicina.

Sarah, assim como demais mulheres dos povos Khoi Khoi, Khoi-San ou Hotentote - na África meridional - chamaram atenção de cientistas europeus por possuírem os "pequenos lábios" vaginais muito maiores do que os ditos "grandes lábios". O termo sinus pudoris - que pode ser traduzido como cortina do pudor e que também é conhecido como "véu da vergonha" - foi utilizado por Lineu na obra Systema Naturae de 1758 para denominar o que, alguns anos depois, o naturalista Georges Cuvier (1769 - 1832) chamaria de "avental hotentote" em seu relatório de dezesseis páginas sobre Sarah Baartman. A cortina do pudor se refere ao que hoje, na medicina ocidental, seria chamado de hipertrofia dos pequenos lábios genitais femininos. Em sua descrição, Cuvier dedica ao menos nove páginas a um relato minucioso acerca da genitália de Sarah, que, enquanto viva, foi exibida em circos europeus em decorrência de suas peculiaridades anatômicas (GOULD, 1990).

Segundo Fausto-Sterling (1995), a descrição de Cuvier sobre a anatomia de Baartman revela em boa medida a insegurança e o medo dos pesquisadores, e da cultura europeia de modo geral, em relação a questões como raça e gênero. Discursos como o de Cuvier evidenciariam o modo como a elite científica francesa se empenhou em propalar seus temores à sociedade da época. Assim como Fausto-Sterling, Blackledge (2004) reflete criticamente sobre a ciência dos séculos XVIII e XIX que, segundo ela, assumiu um viés extremamente racista e sexista ao difundir amplamente as variações de tamanho dos pequenos lábios genitais femininos como evidência de superioridade de uma civilização sobre a outra, estabelecendo padrões de normalidade que relacionam o pouco volume genital a uma maior pureza e feminilidade.

Os discursos de Cuvier, devido à sua fama e centralidade, ganharam proporções diferenciadas e status de verdade, materializando e condensando uma gama variada de concepções sobre a sexualidade feminina que permeavam o imaginário ocidental da época e que sobrevivem até hoje. Por considerar os Hotentotes hierarquicamente mais próximos aos símios e, dessa maneira, menos humanos do que qualquer outro povo ou etnia, o anatomista presumiu que os lábios genitais de outras mulheres africanas seriam menores à medida que estas 


\section{Revista \\ Debates Insubmissos}

se aproximavam da condição biológica de brancos europeus (GILMAN, 1985). Tais compreensões indicam a existência de uma complexa relação entre a patologização da sexualidade feminina, diferentes concepções de humano, padrões estéticos e de saúde cuja epítome é a categoria sinus pudoris.

A história de Sarah Baartman decreta os "excessos", a cor e a sexualidade que de alguma forma parecemos querer negar. Contudo, sua permanência ressoa, atentando para hierarquias raciais e estéticas que persistem ainda hoje. As cirurgias íntimas e a categoria "hipertrofia dos pequenos lábios", quando colocadas em relação à imagem de Sarah e do que ela representa, nos apontam alguns entendimentos acerca de como têm sido materializados os corpos no contexto específico dos aprimoramentos corporais realizados no Brasil. Se os "excessos" da genitália de Baartman são, até hoje, concebidos no terreno do teratológico e disgênico, a medicina atual, entretanto, teria as tecnologias e o senso estético para eliminá-los, trazendo ao corpo o "normal" e o "humano" esperados.

\section{CONSIDERAÇÕES FINAIS}

O caso de Baartman e como a dimensão de seus lábios genitais foi atrelada ao inumano me levou, baseada nos autores e autoras precedentemente citados, a produzir associações com as atuais cirurgias íntimas e os padrões estéticos genitais almejados. As relações não são óbvias e estão a todo momento sendo criadas, seja pelas práticas, seja por quem se dedica a pensá-las. Mas a hipersexualização conferida à Sarah em decorrência de sua cor e do tamanho de sua genitália aponta de modo preciso para uma racialização de certas características corporais. Ao extirparmos estes "excessos" (seja de pele, seja da cor, seja do sexo), vislumbramos uma genitália "pós-humana" e hiperfeminina, contida em suas dimensões e formas. Neste cenário, o que escapa à simetria, à coloração clara e ao pouco volume materializa-se como disforme, primitivo, não humano.

Se nos voltarmos para o contexto brasileiro, as correlações entre cirurgias plásticas e hierarquias estéticas parecem também indicar para uma realidade que caminha no sentido de 
apagar traços entendidos como racializados. Consoante Jarrin $(2015 ; 2017)$, no Brasil, a miscigenação é compreendida em alguns contextos como um processo que nem sempre produziu bons arranjos. Ao contrário, teria fabricado corpos com características dissonantes, que não obedecem à estética de nenhuma etnia em especial, e que as combinam de forma pouco aprazível ao olhar. A cirurgia plástica surgiria como uma forma de rearranjar estes corpos a fim de aproximá-los de uma estética predominantemente europeia. Em relação a isso, Jarrin (2015) aponta que os discursos médicos sobre beleza fornecem uma confirmação biopolítica de hierarquias estéticas que alocam a características físicas de pessoas brancas como mais bonitas e desejáveis.

Ao elaborar uma "dobra temporal" - entre padrões estéticos genitais vigentes e aquilo que Baartman e sua anatomia representam - sugeri um entendimento das cirurgias íntimas como algo que produz "raça" e é por ela produzido. Em outras palavras, essas práticas de intervenção corporal coproduzem novas concepções/materializações de raça, assim como estas últimas fazem emergir tecnologias médicas/estéticas específicas.

Este trabalho pretendeu desenvolver uma narrativa a partir de semelhanças e diferenças - em relação ao corpo masculino, à Sarah Baartman, às ausências, à "hiperfeminilização" que, em conjunto, nos ajudam a pensar raça, gênero e as cirurgias plásticas por meio de aproximações e distanciamentos.

Por fim, talvez seja possível dizer que, nesta discussão especial, algumas "verdades" não se encontram atrás do "véu" 22 , mas precisamente nele.

\section{REFERÊNCIAS}

BATTISTI, Caroline et al. Tratamento da hipertrofia de pequenos lábios vaginais na adolescência-experiência atual do Hospital da Criança Santo Antônio da Santa Casa de Misericórdia de Porto Alegre. Rev. Bras. Cir. Plást. 33(0):175-177, 2018

\footnotetext{
${ }^{22}$ Em analogia aos pequenos lábios genitais de Sarah Baartman, denominados por Cuvier de "véu da vergonha".
} 
BLACKLEDGE, Catherine. A história da V: abrindo a caixa de pandora. 2. Ed. São Paulo: Degustar. 316 p. Tradução: J. M. Bertolote, 2004.

BRAIDOTTI, Rosi. Signs of wonder and traces of doubt: On teratology and embodied differences. In: Price J, Shildrick M, Feminist Theory and the Body. 1st ed. New York: Routledge; p. 290-301, 1999

BRAIDOTTI, Rosi. The Posthuman. 1st ed. Malden, MA: Polity Press, 2013.

BRASIL. Departamento de Informática do Sistema Único de Saúde (DATASUS) [Internet]. Brasília: Ministério da Saúde; 2019. Disponível em: http://www.datasus.gov.br.

BRAUN, Virginia. The vagina: An analysis. Tese de Doutorado. Loughborough University, 2000

FAUSTO-STERLING, Anne. Gender, Race and Nation: The Comparative Anatomy of "Hottentot" Women in Europe, 1815-1817. In: Terry, J; Urla, J, organizadores. Deviant bodies: Critical perspectives on difference in science and popular culture. Indiana: Indiana University Press; p. 19-48, 1995.

FAUSTO-STERLING, Anne. Dualismos em duelo. Cadernos pagu, n. 17-18, p. 9-79, 2002. Disponível em: http:/www.scielo.br/scielo.php?pid=S0104$83332002000100002 \&$ script $=$ sci_abstract\&tlng=pt.

FERREIRA, Jonatas; HAMLIN, Cynthia. Mulheres, negros e outros monstros: um ensaio sobre corpos não civilizados. Revista Estudos Feministas, v. 18, n. 3, p. 811-836, 2010.

FOUCAULT, Michel. Vigiar e punir: nascimento da prisão. Petrópolis, RJ: Vozes, 1999.

GILMAN, Sander L. Black bodies, white bodies: Toward an iconography of female sexuality in late nineteenth-century art, medicine, and literature. Critical Inquiry, v. 12, n. 1, p. 204$242,1985$.

GOULD, Stephen Jay. O sorriso do flamingo: reflexões sobre história natural. São Paulo: Martins Fontes, 1990.

HARAWAY, Donna Jeanne. Primate visions: Gender, race, and nature in the world of modern science. New York: Routledge, 1989

INTERNATIONAL SOCIETY OF AESTHETIC PLASTIC SURGERY. Internacional Survey on Aesthetic/Cosmetic Surgery. ISAPS 2017 [Internet]. 2018. Disponível em: http://www.isaps.org/Media/Default/global-statistics/ISAPS-Results-Procedures-2017.pdf.

INTERNATIONAL SOCIETY OF AESTHETIC PLASTIC SURGERY. Internacional Survey on Aesthetic/Cosmetic Surgery. ISAPS 2018 [Internet]. 2019. Disponível em: 
https://www.isaps.org/wp-content/uploads/2019/12/ISAPS-Global-Survey-Results-2018new.pdf.

JARRÍN, Alvaro. Towards a biopolitics of beauty: Eugenics, aesthetic hierarchies and plastic surgery in Brazil. Journal of Latin American Cultural Studies, v. 24, n. 4, p. 535-552, 2015. JARRÍN, Alvaro. The biopolitics of beauty: cosmetic citizenship and affective capital in Brazil. Oakland: University of California Press; 2017.

JONES, Holly; JONES, Nicholaos. Race as technology: from posthuman cyborg to human industry. Ilha do Desterro, v. 70, n. 2, p. 39-51, 2017.

LAQUEUR, Thomas. Inventando o sexo. Rio de Janeiro: Relume Dumará, 2001.

LILLYWHITE, Austin. Is Posthumanism a Primitivism? Networks, Fetishes, and Race. Diacritics, v. 46, n. 3, p. 100-119, 2018.

MALONE, Jessica et al. Women and genital cosmetic surgery. Women's Health Issues Paper, n. 9, p. i, 2013.

M'CHAREK, Amade. Fragile differences, relational effects: Stories about the materiality of race and sex. European Journal of Women's Studies, v. 17, n. 4, p. 307-322, 2010.

M'CHAREK, Amade. Race, time and folded objects: the HeLa error. Theory, Culture \& Society, v. 31, n. 6, p. 29-56, 2014.

NURKA, Camille. Female genital cosmetic surgery: deviance, desire and the pursuit of perfection. 1st ed. Melbourne: Palgrave Macmillan, 2019.

PRECIADO, Beatriz. Manifesto Contrassexual - Práticas Subversivas De Identidade Sexual. São Paulo: n-1 edições, 2014.

RAGO. Margareth. O corpo exótico, espetáculo da diferença. Labrys, Études Féministes/ Estudos Feministas. Janvier/Juin 2008-Janeiro/Junho 2008.

ROHDEN, Fabiola. Uma ciência da diferença: sexo, contracepçäo e natalidade na medicina da mulher [tese]. Rio de Janeiro: Museu Nacional UFRJ; 2000.

ROSIEK, Jerry. Critical race theory meets posthumanism: Lessons from a study of racial resegregation in public schools. Race Ethnicity and Education, v. 22, n. 1, p. 73-92, 2018.

SCHIEBINGER, Londa. Mamíferos, primatologia e sexologia. In: Porter R, Teich M, organizadores. Conhecimento sexual, ciência sexual: A história das atitudes em relação à sexualidade. São Paulo: UNESP, 1998. 
SPERLI, Aymar Edison; FREITAS, José Octávio Gonçalves De; ANDRADE MELLO, Alieksei Clairefont De. Tratamento cirúrgico da hipertrofia clitoriana. Revista Brasileira de Cirurgia Plástica, v. 26, n. 2, p. 314-320, 2011.

VOLTAIRE, Alain. Dictionnaire philosophique. 1764.

WASHINGTON, Harriet A. Medical apartheid: The dark history of medical experimentation on Black Americans from colonial times to the present. New York: Doubleday Books, 2006.

Submetido: $29 / 01 / 2021$

Aprovado: 12/05/2021 